\title{
Autoavaliação como estratégia de resistência à avaliação externa ranqueadora
}

\author{
Geisa do S. C. V. Mendes \\ João Caramelo" \\ Lisete R. G. Arelaro"II \\ Manuela Terrasêcalv \\ Mara R. L. De Sordiv \\ Sonia M. P. KruppaVI
}

I- Pontifícia Universidade Católica de Campinas, Campinas, SP, Brasil. Contato: geisavaz@gmail.com

II- Universidade do Porto, Porto, Portugal. Contato: caramelo@fpce.up.pt;

III- Universidade de São Paulo, São Paulo, SP, Brasil.

Contato: liselaro@usp.br; skruppa@usp.br IV- Universidade do Porto, Porto, Portugal. Contato: terraseca@fpce.up.pt

V- Universidade Estadual de Campinas, Campinas, SP, Brasil.

Contato: maradesordi@uol.com.br

VI-Universidade de São Paulo, São Paulo, SP, Brasil.

Contato: skruppa@usp.br

\section{Resumo}

Este artigo discute o sentido atual das políticas de avaliação na e $d a$ escola ao apresentar a investigação realizada por pesquisadores brasileiros e portugueses, com a participação de vinte escolas públicas, nas cidades de São Paulo e Campinas (Brasil) e do Porto (Portugal). Referenciando-se na Avaliação Institucional Participativa e na Qualidade Negociada, a pesquisa se junta aos profissionais das escolas e de setores da administração educacional, com a formação de grupos de estudo em cada uma das universidades. 0 artigo aborda criticamente a função expertise da pesquisa que frequentemente legitima avaliações centradas nos produtos, portando credibilidade aos testes padronizados, à proliferação de uma avaliocracia, com consequente alteração de procedimentos de inspeção e direção escolares, além de mudanças na gestão dos sistemas educativos, corrompendo/deformando o conceito de autonomia escolar, favorecendo a proliferação de escolas administradas por concessão, o estímulo ao cheque-ensino, bem como o aumento e naturalização das desigualdades escolares e uma dada representação da sociedade do conhecimento, que refuncionaliza a formação profissional para as classes populares, recriando a dualidade do ensino. Em contraponto, a pesquisa argumenta as possibilidades de um circuito virtuoso do ensino, da pesquisa e da extensão como método na relação com escolas públicas, partindo de uma concepção de Qualidade Negociada que, em conjunto com profissionais e comunidade, em cada escola, inicia processos de autoavaliação, com intencionalidade de transformação e com a possibilidade de desenvolvimento de novas relações dentro e fora da escola, reforçando a aprendizagem estratégica da competência coletiva dos atores sociais em prol da escola pública de qualidade social.

\section{Palavras-chave}

Avaliação Institucional Participativa - Políticas públicas Autoavaliação - Qualidade Negociada. 


\title{
Self-evaluation as a strategy of resistance to the ranking external evaluation
}

\author{
Geisa do S. C. V. Mendes' \\ João Caramelo" \\ Lisete R. G. Arelaro"II \\ Manuela Terrasêcalv \\ Mara R. L. De Sordiv \\ Sonia M. P. Kruppa ${ }^{\text {VI }}$
}

I- Pontifícia Universidade Católica de Campinas, Campinas, SP, Brasil.

Contato: geisavaz@gmail.com

II- Universidade do Porto, Porto, Portugal.

Contato: caramelo@fpce.up.pt;

III- Universidade de São Paulo, São Paulo,

SP, Brasil.

Contato: liselaro@usp.br; skruppa@usp.br

IV- Universidade do Porto, Porto, Portugal.

Contato: terraseca@fpce.up.pt

V- Universidade Estadual de Campinas, Campinas, SP, Brasil.

Contato: maradesordi@uol.com.br

VI-Universidade de São Paulo, São Paulo,

SP, Brasil.

Contato: skruppa@usp.br

\section{Abstract}

This article discusses the current meaning of the evaluation policies in and of school, presenting a study carried out by Brazilian and Portuguese researchers, with the participation of twenty public schools in the cities of São Paulo and Campinas (Brazil) and Porto (Portugal). Theoretically anchored in the Participatory Institutional Evaluation and Negotiated Quality approaches, the research involves the schools' professionals and also sectors of education administration, through the study groups in each of the universities. The article critically addresses the expertise function of the research that frequently legitimizes evaluations centered on products and thus lends credibility to standardized tests and to the proliferation of the so-called evaluocracy, with consequent changes in the school inspection and management procedures, and also in the management of education systems. These changes corrupt/deform the concept of school autonomy and favor the proliferation of concession schools, stimulate the use of education vouchers, as well as the increase and naturalization of school inequalities and a certain representation of the Knowledge Society, which promotes vocational training for the working classes, recreating a dual education system. In contrast, this study argues for the possibilities of a virtuous circle between education, research and extension as a method of relation with public schools, starting from the concept of Negotiated Quality that, together with professionals and community in every school, initiates self-evaluation processes, with the intention of transformation and developing new relationships within and outside the school, reinforcing the strategic learning of a collective competence of social actors in favor of public school social quality.

\section{Keywords}

Participatory Institutional Evaluation - Public policy - Selfevaluation - Negotiated quality 


\section{Introdução}

Desde 2012, pesquisadores de três universidades públicas vêm se aproximando num projeto de pesquisa desenvolvido no âmbito de um acordo de cooperação acadêmica internacional.

Tendo como tema a avaliação educacional, este projeto contrapõe, às atuais políticas e práticas de avaliação externa ${ }^{1}$, a implicação dos atores educativos em processos de autoavaliação, marcados pela reflexão sobre as suas práticas e rotinas de trabalho, analisando tensões entre essas duas lógicas de pensar e praticar a avaliação de escolas e visando à construção de perspectivas e práticas de efetiva melhoria da escola. Ao todo, estão envolvidas vinte escolas, treze no Brasil e sete no Porto, Portugal.

São objetivos deste projeto: estabelecer e consolidar redes científicas no domínio da investigação e da formação pós-graduada; promover debate inovador e fundamentado sobre relações entre avaliação, políticas públicas e qualidade na educação básica; possibilitar a internacionalização da investigação realizada; consolidar um grupo de pesquisa nessa temática; contribuir para a formação pósgraduada; favorecer aproximações mútuas entre a investigação produzida na universidade e os atores sociais do campo político e educacional; construir mecanismos qualitativos

1- Por avaliação externa, entendemos, neste artigo, tanto as avaliações de âmbito internacional, tais como 0 Trends in International Mathematics and Science Study (TIMSS) ou o Programme for International Student Assessment (PISA), quanto as avaliações de âmbito nacional, como, por exemplo, os Exames Nacionais, em Portugal (realizados com todos os alunos de $4^{\circ}, 6^{\circ}, 9^{\circ}, 11^{\circ}$ e $12^{\circ}$ anos), ou, no Brasil, o Sistema de Avaliação da Educação Básica (SAEB), composto por três avaliações externas: a Avaliação Nacional da Educação Básica, que é bianual, de natureza amostral para escolas públicas e privadas, no $4^{\circ} / 5^{\circ}, 8^{\circ} / 9^{\circ}$ anos e no $3^{\circ}$ ano do ensino médio; a Avaliação Nacional do Rendimento Escolar/Prova Brasil, que é bianual, de natureza censitária para escolas públicas, no $4^{\circ} / 5^{\circ}, 8^{\circ} / 9^{\circ}$ anos; e a Avaliação Nacional da Alfabetização (ANA), que é anual, censitária, envolvendo os alunos do $3^{\circ}$ ano do Ensino Fundamental das escolas públicas e o Exame Nacional do Ensino Médio (ENEM), que é facultativo e realizado junto aos que já concluíram e aos concluintes do ensino médio. Também entendemos por avaliação externa os exames realizados pelos sistemas estaduais como o Sistema de Avaliação do Rendimento Escolar do Estado de São Paulo (SARESP). e participativos de avaliação nas políticas públicas da educação.

\section{O contexto da pesquisa}

Essa pesquisa destaca-se por sua posição crítica à avaliação educacional baseada em testes padronizados, na comparação de dados quantitativos descontextualizados e no ranqueamento de escolas que, presentes em diferentes países, não vêm alterando para melhor a qualidade da educação (ARELARO, 2007; RAVITCH, 2011; SORDI, 2013; TERRASÊCA; BERGER, 2011; TERRASÊCA, 2012).

Por suas características, afirma-se na contraposição ao papel que vem sendo atribuído à pesquisa e ao pesquisador da educação, reduzidos a uma função de expertise, como afirma Rochex, analisando os efeitos do Programme for International Student Assessment (PISA), criado pela Organização para a Cooperação e Desenvolvimento Econômico (OCDE), em 1997. 0 autor considera que essa forma de pesquisa tem contribuído para que a avaliação deixe de ser pensada como produzindo indicadores que meçam os efeitos da política e passe a ser ferramenta e técnica da política, visando a influenciar as políticas e as práticas educativas, em nome de evidências e da suposta constatação do que funciona. Pesquisas e pesquisadores, ao mesmo tempo, passam a atender à necessidade de rigor relativamente à elaboração e às metodologias da própria pesquisa, produzindo, também, recomendações fidedignas, além do sentido proclamado de qualidade, de eficácia e de legitimidade dessa forma de avaliar (ROCHEX, 2008).

Nesse caso, a avaliação deixa de ser a busca do sentido da ação educacional para se transformar em seu controle (ARDOINO; BERGER, 1986), “diminuindo-se progressivamente os instrumentos de persuasão ou de socialização profissional e organizacional a favor dos instrumentos para medir o rendimento e a eficácia” (CORREIA, 2010, p. 1). 
Para Correia, estamos frente à criação de uma avaliocracia - uma rede de tecnocratas, um corpo de "especialistas especialmente especializados", nos termos de HAMELINE (1986) - que produz uma linguagem muito sofisticada e tecnicamente instrumentada e que apenas remotamente faz referência à atividade educativa em si (CORREIA, 2008; 2010).

Altera-se a inspeção e os referenciais dos gestores escolares, apoiados nas afirmações de pesquisadores, que dão credibilidade e legitimidade ao procedimento da avaliação e em cuja produção as análises críticas foram se diluindo frente ao domínio das lógicas instrumentais (CORREIA, 2010, p. 2).

Instala-se um processo de transformação gradativo dos direitos educativos, com a perda de suas características universais e públicas e o avanço de uma lógica individualizante e de padronização mercantil, que favorece a privatização da própria formação docente. Considerada como impulsionadora legítima do desejo de êxito e de qualidade, a competição passa a regular o sistema educativo. Ela modela a ação escolar em circuitos curtos, que se retroalimentam a partir da publicação de cada resultado, tal como no modelo administrativo e econômico do just in time, em que a prateleira do supermercado, último elo da cadeia produtiva, dá ordem e ritmo para a produção, diminuindo custos, sob a égide da eficiência e da eficácia. Inverte-se e modifica-se a construção de uma perspectiva formadora, iniciada pela elaboração de um currículo que dialogue com as características da comunidade e do território escolar, capaz de definir aprendizagens significativas e que, acompanhado, desde sempre e não pontualmente, pela avaliação do conjunto das ações empreendidas, possa se modificar no curso do processo educativo.

Dessa forma, a medição pontual de resultados escolares não resolve a questão da qualidade educacional, justificativa inicial dos sistemas de avaliação externa. Talvez porque a força motriz dessa avaliação não esteja na superação das desigualdades educacionais, mas objetive sua legitimação, ao recriar a escola dual com novas propostas de cursos profissionalizantes, considerados adequados às necessidades dos segmentos sociais de menor renda. A desigualdade social é naturalizada na nova ordem econômica da produção flexível e automatizada, com o crescimento incessante de desempregados, submetidos à lógica das exigências, permanentemente recriadas, de novas competências profissionais. Cria-se a representação da "sociedade do conhecimento e da formação permanente ao longo da vida", prescritas aos trabalhadores sem emprego, responsabilizados individualmente por sua desatualização tecnológica, denunciadas no Brasil e em Portugal (FRIGOTTO; CIAVATTA, 2003; ANTUNES, 2005; LIMA, 2005; MORAES, 2013).

0 PISA vem revelando a ampliação das desigualdades escolares dos jovens. $\mathrm{Na}$ Comunidade Europeia, a França passa a ser um dos países onde a distribuição do acesso e da permanência escolar espelha a desigualdade social (ROCHEX, 2013), condição que ameaça sua tradição republicana, pautada pela busca da igualdade de condições.

Em Portugal, como em outros países, de forma complementar à implantação das avaliações externas, muda-se o conteúdo da autonomia das escolas. Por meio dos contratos de autonomia, as escolas são responsabilizadas por seus êxitos ou fracassos; a gestão escolar é chamada a exercer cada vez mais um papel técnico, que desqualifica a política como possibilidade e instala a administração da política (CORREIA; FIDALGO, Fernando; FIDALGO, Nara, 2011; BARROSO, 2011).

Como exame de destaque mundial (CARVALHO, 2011), o PISA vem gerando um forte mercado para a elaboração de testes, para a produção de materiais e para a formação de professores e "a escola, o grande mercado do século XXI” (SELYS, 1998), é denunciada na grande imprensa europeia, já em 1998.

No Brasil, no circuito de ampliação do neoliberalismo, "as avaliações estandardizadas são implantadas com maior vigor a partir dos 
anos noventa, impulsionadas por organismos multilaterais como o Banco Mundial” (KRUPPA, 2014, p. 40). Grupos econômicos, na forma de fundações privadas ou de movimentos sociais, aparecem com propósito de melhoria da educação. 0 Movimento Todos pela Educação, organizado no Brasil em 2006, com forte representação do setor empresarial e defensor das classificações das escolas de acordo com os resultados das avaliações externas, atua como se fora um agente regulador do poder público, reproduzindo práticas da mídia conservadora, frequentes em outros países (BARROSO, 2003; FREITAS, 2012a).

Ressurge o lema da liberdade de escolha e do cheque ensino, justificados pela suposta insuficiência de recursos de um Estado que assume novas funções na condução do sistema educativo - a do Estado Provedor das condições para a realização do direito à educação para o Estado Regulador, que descentraliza certas tarefas para as localidades, refuncionalizando o conceito de autonomia escolar (BARROSO, 2003; BARROSO; AFONSO, 2011), como é anunciado pelo governo português, na Reforma Política de $2013^{2}$.

Em vários locais da Europa e América, amplia-se a criação de escolas administradas por concessão, fortalecendo uma rede de empresas privadas: na Suécia, a empresa Bure Equity e as escolas independentes friskolor, na Inglaterra, as academy schools, nos Estados Unidos, a Fundação Heritage e as escolas charter (RAVITCH, 2011; SALOKANGAS, 2013).

Cabe, portanto, indagar sobre a formação de uma "Agenda Globalmente Estruturada para a Educação", em que operam "forças econômicas supra e transnacionalmente para romper ou ultrapassar as fronteiras nacionais, ao mesmo tempo em que reconstroem as relações entre as nações” (DALE, 2004, p. 426), ensejando que "repensemos os modos como a sociologia da educação aborda conceitos como nacional, educação e sistemas" (DALE, 2010, p.1099).

2- Governo de Portugal. Um estado melhor. Proposta do governo, aprovada no Conselho de Ministros de 30/10/2013, p. 69-78.

\section{Para que e a quem servem iniciativas de contrarregulação?}

No quadro de contraposição de conceitos e de opções políticas é que se situa a avaliação institucional e os procedimentos de autoavaliação, estudados e desenvolvidos por esta pesquisa. Reconhecer a centralidade da avaliação externa no texto e no contexto das atuais políticas educacionais exige tomada de posição que ultrapasse a mera denúncia de equívocos. 0 que está em jogo é a qualidade na e da escola pública e as inegáveis repercussões para aqueles (não poucos) que dela dependem e aos quais se deve assegurar o direito de acesso, permanência e aprendizagens detentoras de qualidade social.

Por isso, não banimos a avaliação dos cenários educativos, mas conclamamos a produção de outras possibilidades. A luta por uma nova epistemologia da avaliação (a da complexidade) precisa disputar, palmo a palmo, a cena política, acercando-se do fenômeno com outro olhar, com significação aberta. Isso auxiliará a que se recupere o sentido da educação, ultrapassando o ethos de um serviço social eficiente, mais ligado aos meios que aos fins, introduzindo-se a luta pelos sentidos da qualidade social que deve ordenar o processo formativo, sabendo-se que os fins não são entidades etéreas, mas construções humanas, engendradas nas lutas de que participamos (DIAS SOBRINHO, 2005).

Falar de qualidade exige esforço elucidativo dos significados, nada unívocos, desse conceito. A escola é um lugar de vários mundos, lugar cruzado por imperativos diferentes e isso afeta a qualidade educativa e define sua natureza polifônica (DEROUET, 1992). Estamos diante de princípios argumentativos diversos; lógicas e racionalidades diferentes afetam a noção de qualidade por conflituarem entre si.

Pertinência social, equidade, enraizamento na realidade concreta onde se dão as práticas educativas, entendimento do conhecimento como forma de contribuir para 
o mundo e não apenas como instrumento pragmático de inserção no mercado, atenção aos valores da liberdade, solidariedade, alteridade são marcadores que devem referenciar qualitativamente os processos avaliativos. Com base nesses princípios, somos desafiados para novas leituras das políticas de avaliação, capazes de acionar perspectivas potencialmente mais críticas no campo da resistência propositiva (FREITAS et al., 2012b; FREITAS, 2012a).

Partimos do pressuposto de que a naturalização da avaliação (MACHADO, 2010) precisa ser desconstruída, afirmando outra narrativa que recupere a dimensão formativa da avaliação, assumindo o pilar da emancipação como aquele que ancora o processo avaliatório da qualidade dos estabelecimentos educativos. A ideia é reforçar a lógica de internalidade e o poder dos atores locais na vocalização da qualidade que se quer legitimar. Reações propositivas a políticas de avaliação produtocentradas precisam ser engendradas no interior da escola, lócus que reúne forças sociais que coletivamente precisam interrogar-se acerca dos sentidos do que fazem e do que elegem fazer, substituindo um fazer mecânico pelo intervir crítico e eticamente implicado.

Resistências propositivas para refrear os efeitos das aprendizagens de cunho utilitarista impostas à juventude e que dela subtraem oportunidades de desenvolvimento humano, especialmente no campo dos valores, desprezados nas formas hegemônicas de avaliação que respondem aos interesses mercadológicos.

Isso nos remete a indagar: por onde passam os saberes da avaliação que circulam nos cursos de formação dos profissionais da educação? Uma visão política, porque implicada em escolhas e que comporta complexidade, precisa voltar a habitar nossas escolas, tanto na formação inicial como continuada dos professores.

A relocalização da avaliação no nível da escola tem ajudado a interiorizar tal debate. Esse lócus, sob os auspícios de uma gestão democrática, propicia a reaproximação dos atores sociais, instigando-os a refletirem e deliberarem sobre os rumos do projeto educativo - fortalece-se o protagonismo dos atores e a possibilidade reconfigurativa das práticas. A avaliação passa a cumprir outro papel, deixando de ser um fim em si mesmo para ser um meio carregado de potencialidade pedagógica e política. Nessa perspectiva, a Avaliação Institucional Participativa (AIP) é considerada essencial para elevar o engajamento de todos os atores no processo de qualificação da escola (LEITE, 2005).

Escolas que trabalham com a comunidade local portam-se como centros irradiadores de lógicas avaliativas emancipatórias, as quais não se furtam ao controle social sobre os resultados dos processos que desenvolvem e que podem ser obtidos de forma mais integradora, aproveitando saberes $\mathrm{e}$ experiências, equivocadamente descartados pelas politicas educacionais mais preocupadas com os índices obtidos pelos estudantes nos exames nacionais ou internacionais, sem interrogar como estes são obtidos. Nesses espaços, a inclusão dos diversos atores aprofunda a reflexão, intensificando o debate acerca da qualidade necessária, frente às demandas do contexto. Orientam-se por processos deliberativos, comprometendo a todos com uma concepção de qualidade socialmente pertinente, devidamente pactuada em favor de todos os estudantes, em especial os socialmente fragilizados.

Parece necessário escapar da cilada de apenas discursar sobre a AIP sem que se preste atenção ao sentido da práxis que ocorre no interior das escolas. Se levarmos em conta que as escolas estão inseridas em cenários traçados para que cumpram certas funções sociais, como a legitimação das diferenças sociais pelo viés das credenciais escolares e a indução de subjetividades submissas e conformadas a sua sorte com introjeção do viés meritocrático, parece-nos que o desafio da qualidade se 
complexifica. Isso nos remete ao campo da luta pela qualidade da escola pública para todos e requer, portanto, espaço e instrumentalização para que as escolas participem do processo de qualificação, o que supõe a aprendizagem da demanda bilateral e da negociação em nome dos interesses dos estudantes. Responsabilização partilhada, qualidade negociada é resultante desse arranjo (SORDI, 2013; FREITAS, 2005).

Nesse sentido, são bem-vindas investigações sobre o que ocorre no interior das escolas submetidas a essas formas de regulação. As universidades públicas devem ser desafiadas a promover a reflexão sobre essas questões, a romper com críticas sobre como as escolas se comportam, e a produzir pesquisas não mais sobre as escolas e sim com as escolas, buscando refazer alianças estratégicas. Trata-se de instituir comunidades de aprendizagem e de práticas interpretativas, antecipando processos decisórios igualmente compartilhados e plurais.

Mas aí a valorização de uma qualidade educacional detentora de pertinência social confronta-se com a cultura da performatividade, presente também nas universidades, resultante de práticas gestionárias eficazes e vorazes. Nessas, a performatividade é uma luta pela visibilidade (BALL, 2005).

Segundo Ball, o gerencialismo desempenha o importante papel de destruir os sistemas éticoprofissionais existentes nas escolas, provocando sua substituição por sistemas empresariais competitivos, e, exatamente contra essa corrente, a política de AIP tenta desenvolver-se.

Assim como a instituição performativa, o pós-profissional é concebido como simplesmente aquele que responde aos requisitos externos e a objetivos específicos, equipado com métodos padronizados e adequados para qualquer eventualidade, é a alienação profissional. Seu profissionalismo é inerente à disposição e habilidade para se adaptar às necessidades e vicissitudes da política.

Observa-se que essa leitura de profissionalismo não pode ser aplicada a uma política de avaliação que se ancora exatamente no restabelecimento dos valores da participação democrática, do diálogo includente e crítico e do fortalecimento dos atores para os atos deliberativos que impulsionam o agir da escola na direção dos interesses da coletividade. Dessa forma, a democracia e o diálogo includente integram a luta crítica, o estranhamento ao trabalho docente alienado por essa imposição de profissionalismo.

Fortalecidos pela e na ação comum, os atores ampliam as possibilidades de seu caminho rumo ao "inédito-viável" para designar o devir, o "ainda-não", o futuro a se construir, o projeto a se realizar (FREIRE, 2008). Neste caso, a utopia está simultaneamente no ato de denúncia do mundo desumano e no anúncio do mundo humano a ser construído por nossa ação transformadora. Somente nessa perspectiva faz sentido uma práxis avaliativa emancipatória, ou seja, uma práxis que se exercita em situação (SAUL, 1988).

Políticas de avaliação comprometidas com o fortalecimento dos atores da escola ensejam um profissionalismo que restitua a dignidade do professor, colocando em relevo a produção de novos conhecimentos e que conclamam os públicos locais a se engajarem na defesa da escola pública de qualidade.

\section{A pesquisa - construindo relações entre universidade, escola e políticas públicas}

0 relato a seguir está circunscrito a um breve histórico do projeto em cada contexto, às principais problemáticas enfrentadas pelas escolas e às questões que apresentam relativamente à avaliação externa e às ações que elas passaram a desenvolver a partir da parceria estabelecida.

\section{0 projeto em São Paulo (Brasil)}

Em São Paulo, em 2013, constituiu-se o Grupo de Estudo e Pesquisa da "Avaliação Negociada" (FREITAS, 2005), resultado de um curso de extensão sobre o tema, com 
a participação dos pesquisadores das três universidades envolvidas no projeto. Em seguida, no I Seminário Internacional de Avaliação, organizado pelos pesquisadores do projeto na Faculdade de Educação da Universidade de São Paulo (FEUSP), os participantes do grupo problematizaram a situação de suas escolas, consolidando o procedimento metodológico adotado - partir sempre do diálogo entre as escolas.

Profissionais (na maioria diretores e coordenadores pedagógicos) de cinco escolas públicas da cidade de São Paulo, perfazendo todos os níveis da educação básica e, ainda, profissionais de setores regionais dos sistemas de educação (supervisores e coordenação regionais) garantiram diversidade ao Grupo de Estudo e Pesquisa, que se reúne, quinzenalmente, para discutir textos teóricos e o cotidiano escolar. A pesquisa interage com escolas e setores regionais do sistema, a partir de ações desencadeadas pelos componentes do grupo.

Outro fator facilitador da aproximação da pesquisa às escolas é a itinerância do local das reuniões. A escola visitada ocupa parte do tempo para uma exposição sobre seus projetos e desafios, em que participam diferentes profissionais e alunos. Em decorrência, consolida-se o próprio grupo, com reflexões melhor fundamentadas nas diferentes realidades. A avaliação negociada afirma a importância da comunicação interescolas, a expressão de singularidades e identidades de escolas que aprendem umas com as outras sem competir, assegurando a prestação de contas da escola pública ao incentivar que as comunidades escolares participem de suas ações. 0 grupo vem estimulando que cada escola reflita sobre seu próprio andamento, resgatando a memória escolar, que pode estabelecer uma nova relação entre as comunidades interna e externa das escolas, ampliando a interação entre os segmentos. As escolas vêm realizando levantamentos do perfil de seu alunado e visitas a suas casas, como formas importantes para a construção da qualidade educacional de sua atuação.
A avaliação negociada é um acordo de futuro, a construção de uma mesma linguagem entre os segmentos escolares na definição de objetivos e ações, ampliando entendimentos e ultrapassando o lamentar imobilizante acerca dos problemas. Nesse sentido, tem-se buscado conhecer e problematizar os projetos das escolas, a partir de questões tais como: quem são seus autores, por que, para quê e para quem eles foram feitos, como os segmentos escolares podem se apropriar deles? Isso tem suscitado a revisão do Projeto Político Pedagógico das escolas e da própria Divisão Regional de Educação, envolvida na formulação e implementação de seu planejamento estratégico, atividades fundamentais para a Avaliação Institucional Participativa (AIP) ou negociada.

As escolas vêm se exercitando em diferentes registros, inclusive em formato de vídeos, apresentados nos seminários da pesquisa. A questão do espaço físico, as grades limitadoras dos contatos entre os segmentos da escola, a gestão de conflitos e a busca de uma dimensão pedagógica na relação entre direção, professores, funcionários, pais e alunos, a importância da formação da equipe escolar são temas recorrentes que vêm ensejando diferentes ações. Assuntos do currículo oculto escolar têm sido abordados, como: homossexualidade e sexo na adolescência, comportamentos religiosos, preconceitos e discriminaç̧ões de diferentes tipos, uso de drogas e violência na escola. Ainda, a questão do descompasso entre crianças e jovens imersos em tecnologias versus as dificuldades dos professores com essas ferramentas.

Desafios dos setores regionais dos sistemas têm sido problematizados, especialmente os relativos ao papel da supervisão escolar, uma vez que a avaliação negociada propõe a superação da dicotomia entre o administrativo e o pedagógico e questiona o controle legalista. 0 grupo percebe que a união entre escola e comunidade pode melhorar formas de convivência nas escolas, nas famílias e na cidade, e vem buscando realizar encontros de alunos dessas escolas, revitalizar grêmios e 
formas participativas nos diferentes conselhos de escola - alguns estabelecimentos já estão com a comunidade presente nos conselhos de classe, onde são discutidas as avaliações individuais de aprendizagem. No bojo de um amadurecimento reflexivo, começa-se a indagar como o conhecimento produzido na múltipla atuação da escola pode se integrar às situações de ensino-aprendizagem da sala de aula, no sentido de novas propostas curriculares, e vem se iniciando a avaliação das implicações dessa ação frente à padronização e às exigências da avaliação externa.

Em decorrência, vem sendo construída uma pauta de formação que aprofunde esses temas, a ser realizada como atividade de extensão da universidade envolvida. A pesquisa na cidade de São Paulo inscreve-se num processo que se pretende não pontual e que não se esgote com o fim do tempo regular do projeto. Características da universidade, centro formador de professores em cursos de Pedagogia e de licenciatura, corroboram essa possibilidade. Algumas das escolas do projeto integram um programa de estágios, formado por escolas públicas consideradas como local privilegiado para estágios dos alunos e futuros docentes. Como método, este projeto vale-se do entrelaçamento entre a pesquisa, o ensino e a extensão. Os textos teóricos apresentados são discutidos à luz da dinâmica das escolas e da formação dos educadores. Ao longo das reuniões, vem se constatando uma mudança de qualidade nas propostas e na intervenção dos membros do grupo, que buscam, a par das diferenças locais de cada escola, socializar procedimentos e práticas exitosas, discutindo e aprofundando a reflexão sobre os fatos apresentados, confrontando os resultados da avaliação externa a partir da problemática vivida em cada unidade escolar. Contrasta o desânimo institucional provocado pelos resultados da avaliação externa com a vontade de atuar manifestada nos encontros do grupo.

Os integrantes do grupo de pesquisa esperam que o desenvolvimento do projeto possa ter influência nas políticas públicas de educação. Por isso, desde o início, há o cuidado dos pesquisadores em informar as ações realizadas aos gestores da política em nível regional e municipal. Acreditamos que este projeto possa contribuir para renovar a antiga proposta dos Centros Regionais de Pesquisa (CRPE), criados por Anísio Teixeira, em 1955. Atuando num momento democrático, uma das características dos CRPE foi considerar a diversidade regional brasileira como um aspecto relevante para a análise e interpretação dos processos de mudança social em curso e, consequentemente, para a elaboração de novas políticas públicas.

Como uma questão mais complexa, vem sendo buscada a construção de indicadores que favoreçam o processo de autoavaliação. Mas não queremos sugerir indicadores para a padronização e ou nivelamento curricular e, sim, discutir e analisar aqueles que respeitem a diversidade, estimulando a produção curricular de cada escola. Pretendemos propor indicadores sobre as condições materiais para o trabalho pedagógico, igualmente valorizado e reconhecido em suas diferentes dimensões da formação continuada à remuneração - que analisem as condições do exercício na escola pública e não apenas dos resultados individuais dos alunos relativamente à aprendizagem de algumas disciplinas; quer-se a avaliação de conjunto da política educacional, que saia do indivíduo isolado para focar-se no sistema, dando condições de qualidade de vida escolar aos alunos.

Temos ciência de que a razão estatística pode entrar em conflito com outras razões, incomensuráveis com ela, ligadas, por exemplo, à irredutível singularidade dos indivíduos, sendo a explicitação desta tensão uma das questões mais importantes no estudo do lugar do argumento estatístico no espaço público (DESROSIÈRES, 1993).

A pesquisa vem apontando as diversas dimensões da avaliação institucional e propostas de autoavaliação, presentes em Portugal, como 
o PAVE - Perfil de Autoavaliação da Escola (MACBEATH et al, 2008) - ou no Brasil, como o INDIQUE - Indicadores da Qualidade na Educação (AÇÃo EDUCATIVA et al, 2007) - têm sido objeto de discussão pelo grupo.

\section{0 projeto em Campinas (Brasil)}

A pesquisa dá continuidade a um conjunto de estudos, que toma a Secretaria Municipal de Educação (SME) de Campinas como cenário privilegiado de experimentação de políticas alternativas de avaliação e que recupera o protagonismo dos vários atores sociais implicados na construção da qualidade educacional da escola pública.

Os desdobramentos do Estado Avaliador, entendido como instrumento de gestão em contexto de reformas educacionais, e a discussão sobre suas repercussões nefastas, dada a ênfase na responsabilização das pontas, em detrimento de uma visão mais ampliada do fenômeno da qualidade educacional, tem sido um desafio aos educadores. Um laboratório de observação vem assumindo esta linha de pesquisa como eixo de seu trabalho, envolvendo um conjunto de pesquisadores (mestrandos, doutorandos e alunos de iniciação científica, além de professores da rede municipal de Campinas), que semanalmente se reúnem para refletir sobre os rumos da educação pública e as repercussões das políticas de avaliação sobre as escolas e as aprendizagens dos estudantes.

Algumas redes de ensino têm reagido às pressões da avaliação sistêmica, criando alternativas avaliativas que recuperam o protagonismo dos atores locais, envolvendoos em processos de Avaliação Institucional Participativa (AIP), deflagrados como políticas de governo, proclamando como princípios fundantes aqueles ligados à avaliação regida pelo pilar da emancipação, como é o caso da rede de Campinas.

Essa rede municipal de ensino é alvo desta investigação, cujo recorte é a qualidade da escola pública: um estudo longitudinal para sustentação da responsabilização partilhada. Estudos indicam que tal rede aparece como vanguarda em processos de cunho contrarregulatório (SOUZA; SORDI, 2012), o que nos remete a estudar as lacunas que precisam ser preenchidas ao longo dos anos de implementação da AIP nessa rede. Consideramos que essa política, pelos princípios que demarcam seu projeto de avaliação, tem favorecido a organização das forças progressistas da escola, ampliando seu protagonismo de modo a engendrarem processos de responsabilização participativa, que se referenciam no ideário da qualidade social, confrontando-se com os interesses mercadológicos que subjazem aos processos de avaliação externa, nacionais e internacionais, que apostam na distribuição de bônus (reais ou simbólicos) como elementos capazes de mobilizar os coletivos a trabalharem em busca de melhores resultados escolares estampados nos índices sazonalmente divulgados.

Cabe, portanto, perscrutar se a AIP como política tem sido capaz de induzir e organizar os coletivos da escola a manter-se na luta pela escola pública de qualidade, mas uma qualidade de outra ordem e não apenas aquela tributária de êxitos efêmeros no ranqueamento do governo federal.

Importante ressaltar que a política de avaliação na rede municipal de Campinas tem incorporado, até o momento, os valores da participação, da gestão democrática e se vale da categoria da negociação inter-atores e instâncias como força motriz do processo de qualificação das escolas. Entendida como instrumento mediador entre o que existe e o que precisa ser (re)construído para que a escola pública tenha qualidade para todos, a negociação é categoria decisiva a ser apr(e)endida pelos diferentes atores, de modo a poderem participar de forma autêntica e ativa da avaliação.

Coerente a esses princípios, a pesquisa em andamento toma como preocupação investigar, inicialmente, junto a oito escolas da rede previamente selecionadas, eventuais sentidos da 
qualidade social que essas pensam desenvolver. Buscou-se identificar os entendimentos que o coletivo escolar tem sobre qualidade social por meio de diversos recursos metodológicos, tais como: análise documental (Projeto Pedagógico, Plano de Avaliação); entrevistas individuais com membros das equipes gestoras; grupo focal inter escolas; e observação dos espaços coletivos, como, por exemplo, Trabalho Docente Coletivo (TDC), Comissões Próprias de Avaliação (CPA) e outros.

Tendo por norte a pergunta "O que a escola faz que considera expressão de qualidade do seu trabalho e que não é captado pelos exames externos?”, elaborou-se um conjunto de dimensões que pretendem responder ao constructo qualidade social, que permitirá melhor entender as melhorias obtidas desde a implementação da AIP nessa rede de ensino. Desejamos produzir avanços nesse campo de pesquisa: pela explicitação da matriz de formação que possibilita a qualidade social da escola pública; e pela descrição e eventual seleção de categorias que ajudem a expressar os sentidos da qualidade social assumidos pelo grupo de pesquisa. Por meio do estudo desenvolvido nas oito escolas, inicialmente, pretende-se avançar na direção de um olhar avaliativo mais ampliado, abarcando a totalidade de escolas de ensino fundamental da rede, em um esforço de apreensão de eventuais avanços no constructo de qualidade social quando se opta pela estratégia de AIP como recurso usado pelas escolas para aprimorar seu projeto educativo.

Como entraves ao processo em desenvolvimento, citamos as constantes alterações do poder público da rede, o que nos obriga a repactuar metas e explicitar referenciais de avaliação frequentemente. Outrossim, observamos que a presença da universidade, investigando e assessorando o projeto de AIP, tem auxiliado a organizar as comunidades escolares para lutarem por sua titularidade na definição da qualidade da escola pública que querem construir.

\section{0 projeto em Porto (Portugal)}

0 trabalho com as escolas no Porto resulta de um projeto anterior, cuja finalidade última era apoiar a construção de modelos de autoavaliação próprios de cada um dos agrupamentos de escolas participantes. 0 grupo de pesquisa envolvia docentes, investigadores e membros das equipes de autoavaliação dos agrupamentos.

A intervenção se orientou pelos princípios da investigação-ação participativa e a principal forma de trabalho consistiu na realização de sessões de formação com os professores, sendo os investigadores da universidade os facilitadores de processos de reflexão e de transformação. 0 resultado mais importante do projeto foi a mobilização das equipes de autoavaliação e da comunidade educativa no geral, para uma análise crítica sobre suas práticas educativas e sobre os sentidos - na dupla acepção da palavra, ou seja, significados e direções - para a transformação dessas práticas.

0 Agrupamento de Escolas de Miragaia local privilegiado de atuação desta investigação, mesmo sem integrar a primeira pesquisa - foi tendo algum envolvimento, designadamente, participando nos seminários internacionais organizados em cada ano do projeto, e foi mostrando um grande interesse pelos modos de trabalho desenvolvidos. 0 acompanhamento da autoavaliação desenvolvida nesse agrupamento, agregado ao projeto de investigação participada no âmbito do atual Convênio Internacional e Pesquisa, assentou na premissa de que as transformações e as melhorias nas escolas só se concretizam se implementadas a partir do seu interior e tendo como protagonistas os atores educativos: professores, alunos, lideranças, lideranças intermédias e pais.

Em 2010, por decisão ministerial, o Agrupamento de Miragaia se juntou a um outro, passando o novo Agrupamento a designar-se Agrupamento de Escolas Rodrigues de Freitas. Essa alteração foi bastante significativa, já 
que as realidades escolares e comunitárias são muito díspares entre um e outro agrupamento. 0 Agrupamento de Miragaia insere-se num contexto de grande desfavorecimento social, tem um projeto educativo especificamente concebido para fazer frente às dificuldades de aprendizagem e para promover o sucesso educativo de suas crianças e jovens, sendo reconhecido como um dos Territórios Educativos de Intervenção Prioritária (TEIP) em Portugal - os quais se beneficiam de maior flexibilidade para a contratação de professores e outros profissionais que se identifiquem e contribuam positivamente para a concretização das finalidades do projeto educativo. Rodrigues de Freitas é uma escola reputada pelos bons resultados dos seus alunos de classe média e média alta. Assim, a junção dos agrupamentos não levou em conta as suas diferenças fundamentais. Para além de objetivos diferenciados, os agrupamentos se distanciam também no que respeita à cultura de autoavaliação e aos modos de trabalho em autoavaliação. Em Miragaia, estes estão já bem consolidados, após alguns anos de mobilização e criação de sinergias entre professores e o restante da comunidade educativa, reflexão sobre as suas práticas e implementação de medidas para a melhoria das aprendizagens e resultados dos alunos. Em Rodrigues de Freitas, esse trabalho está apenas no seu início, sendo grande o esforço no sentido de mobilizar quer professores quer o conselho pedagógico no debate acerca da função docente, das finalidades da escola pública e dos modos de trabalho pedagógico. No novo agrupamento de escolas, é notória a preocupação com os resultados dos alunos, bem como com a resposta às injunções permanentes que a administração e a inspeção fazem às escolas e às suas direções.

Nos últimos anos, tem crescido o impacto da dimensão dos resultados dos alunos na avaliação das escolas, com repercussões ao nível dos apoios que lhes são dados. À imagem e ao estigma social promovidos pelos ranqueamentos, realizados e divulgados pela mídia, com base nas classificações obtidas pelos alunos nos exames nacionais, junta-se o peso que os resultados dos alunos têm na atual Avaliação Externa das Escolas, organizada pela Inspeção-Geral da Educação e Ciência e, para os TEIP, o fato de esses resultados funcionarem como o barômetro que ditará a continuidade do financiamento do projeto educativo - consoante consigam, ou não, atingir ou superar as metas previamente estabelecidas.

Considerando a relevância que é atribuída por estas duas formas de avaliação externa aos resultados dos alunos, cremos que a autoavaliação não pode ficar indiferente. No trabalho com as escolas nesta pesquisa, o que se tem procurado fazer é que a urgência de responder a essas injunções externas não impeça um trabalho de outra natureza, mais reflexivo e holístico sobre o trabalho educativo do Agrupamento e sobre essas injunções.

Nas escolas do Porto, decorreram sessões de formação com os professores, sob o tema "Aproximar resultados da avaliação interna e externa - desenvolver ações que promovam aprendizagens aprofundadas”. Pretendia-se: a) propor estratégias inovadoras, no domínio da avaliação educacional, para melhorar o desempenho geral do Agrupamento, inclusive os resultados dos alunos; b) refletir sobre processos de avaliação desenvolvidos em diversas disciplinas/áreas disciplinares; c) analisar e interpretar, a partir da perspectiva do docente, modos de avaliar em uso; d) construir processos de avaliação equilibrados, incluindo testes/exames; e) problematizar relações entre autoavaliação, avaliação externa e avaliação das aprendizagens.

Por as considerarem mais prementes, os professores optaram por focar a autoavaliação nas questões respeitantes ao trabalho realizado em sala de aula. Identificada a indisciplina como um problema importante que interfere nas atividades de ensino-aprendizagem, a formação se iniciou de acordo com a metodologia de análise de incidentes críticos, a partir de casos de indisciplina relatados pelos 
professores participantes. Uma segunda fase se centrou na análise quer de testes cedidos pelos professores, quer de exames nacionais para cada um dos diferentes anos e disciplinas. Em grupos, os professores analisaram as questões dos enunciados no que concerne à clareza da redação, processos cognitivos requeridos e adequação e pertinência do conteúdo, tendo como referência as finalidades das disciplinas e os contextos de vida dos alunos.

Com o intuito de apoiar a realização de uma análise mais aprofundada dos exames, foi adaptada e usada a matriz Test Accessibility and Modification Inventory (TAMI), que avalia a acessibilidade de perguntas de testes, matriz essa elaborada por investigadores norteamericanos que têm se dedicado a pesquisar tais questões (BEDDOW; ELLIOTT; KETTLER, 2009). A reflexão proporcionada permitiu: por um lado, o contato com a forma, conteúdo e grau de dificuldade dos testes produzidos pelos professores do próprio agrupamento - alguns deles participantes da formação - e a produção compartilhada de um olhar crítico sobre os mesmos; por outro lado, o confronto entre as características dos testes do agrupamento e as dos exames nacionais que os alunos realizam, com implicações na sua classificação final e, consequentemente, na possível transição ou não de ano letivo. Contudo, a principal valia dessa reflexão residiu na capacidade de os professores se darem conta da ausência de sentido que alguns tipos de itens pressupõem, os quais apelam quase exclusivamente à memorização e à descontextualização dos saberes, impelem os alunos para uma relação de exterioridade e de desimplicação face aos conhecimentos adquiridos em contexto escolar, tornando-os pouco relevantes e, até mesmo, descartáveis. Desse modo, a autoavaliação torna-se uma possibilidade efetiva de partilha, de reflexão e de transformação das práticas educativas, constituindo-se contributo para a sua adequação às pessoas que habitam as escolas e que nelas continuamente são formadas e se formam.

\section{Uma conclusão provisória}

A iniciativa de pesquisadores das três universidades que constituem este projeto é seguramente marcada pelo compromisso com uma qualidade negociada (BONDIOLI, 2004; FREITAS, 2005), pactuada entre os sujeitos da escola - comunidade interna e externa.

Diferentes formas de reagir propositivamente estão sendo construídas. Reconhecidas as diversidades das experiências da pesquisa, parece-nos crucial destacar convergências, pois todas ocorrem com o apoio de universidades públicas, engajadas na luta por um projeto educativo com qualidade social, sob a égide de uma investigação em que os partícipes ensinam-se mutuamente, conduzidos a partir de uma concepção de qualidade negociada, que se inicia com movimentos de autoavaliação e que avança na direção da interpelação das práticas vividas, com clara intencionalidade de transformação da realidade em favor de segmentos sociais mais fragilizados.

Essa recomposição de forças pode jogar a favor do desenvolvimento de novas relações dentro e fora da escola, reforçando a aprendizagem estratégica da competência coletiva dos atores sociais em prol da escola pública de qualidade e contribuindo para

[...] configurar uma accountability democraticamente avançada, o que inclui a avaliação, a prestação de contas e a responsabilização, pressupondo relações e conexões abertas, problematizáveis e susceptíveis de se aperfeiçoarem ou reconstituírem, e que se legitimem ou se sustentem em valores e princípios essenciais, a cidadania crítica, a participação, o empowerment, o direito à informação, a transparência e a justiça, entre outros (AFONSO, 2012, p. 478).

Esse processo começa a dar sinais das potencialidades de trabalhos que primam por construções coletivas em que se enxerga o 
protagonismo de cada um no processo, em que a autoavaliação impulsiona o pensar sobre si e sobre o outro. Nesse sentido, emerge a contrarregulação assentada em um planejamento de ações fundada em princípios éticos, políticos e epistemológicos, a qual ajuda a escola a concretizar um modo de fazer avaliação que se singulariza face aos novos desafios.

No projeto, a articulação entre a universidade pública e a escola de Educação Básica fomenta, por um lado, a qualificação da educação no interior da escola, colaborando para estudos no interior da universidade e, por outro lado, vislumbra dar subsídios a todos os envolvidos com o processo de fortalecimento das escolas para o enfrentamento das políticas de responsabilização vertical orientadas pelos resultados dos estudantes nas avaliações externas. Contribui, ainda, para a afırmação da identidade da universidade, ao cumprir com o princípio da indissociabilidade entre ensino, pesquisa e extensão, desempenhando a sua função social a serviço do desenvolvimento social, econômico e cultural. Desse modo, implementam-se: os processos de transmissão e apropriação do saber historicamente sistematizado, por meio do ensino; os processos de construção do saber, propiciados pela pesquisa; e os processos de objetivação ou materialização desses conhecimentos, por meio da intervenção na realidade, a extensão.

\section{Referências}

AÇÃO EDUCATIVA et al. (Coords). Indicadores de Qualidade da Educação. 3. ed. aum. São Paulo: Ação Educativa, 2007.

AFONSO, Almerindo J. Para uma conceptualização alternativa de accountability em educação. Educação \& Sociedade, Campinas, v. 33, n. 119, p. 471-484, abr./jun. 2012.

ANTUNES, Fátima. Globalização e europeização das políticas educativas: percursos, processos e metamorfoses. Sociologia, Problemas e Práticas, Oeiras, n. 47, p. 125-143, jan. 2005.

ARDOINO, Jacques; BERGER, Guy. L'évaluation comme interprétation. Tradução Manuela Terrasêca. Pour, no 107, p. 120-127, jun./ago. 1986.

ARELARO, Lisete. Formulação e implementação das políticas públicas em educação e as parcerias público-privadas: impasse democrático ou mistificação política? Educação \& Sociedade, Campinas, v. 28, n. 100, p. 889-919, out. 2007.

BALL, Stephen J. Profissionalismo, gerencialismo e performatividade. Cadernos de Pesquisa, São Paulo, v. 35, n. 126, p. 539564, set./dez. 2005.

BARROSO, João. (org). A Escola Pública: Regulação, desregulação e privatização. Porto, Portugal: ASA Editores, S.A., 2003.

BARROSO, João; AFONSO, Natércio. (org). Políticas educativas: Mobilização de conhecimento e modos de regulação. Porto, Portugal: Fundação Manuel Leão, 2011.

BEDDOW, Peter. A.; ELLIOTT, Stephen N.; KETTLER, Ryan. J. TAMI: accessibility rating matrix. Nashville, TN: Vanderbilt University, 2009.

BONDIOLI, Anna. (Org). 0 Projeto pedagógico da creche e a sua avaliação: a qualidade negociada. Campinas: Autores Associados, 2004.

CARVALHO, Luis M. (Coord). 0 Espelho do Perito: Inquéritos internacionais, conhecimento e política em educação - 0 caso do PISA. Porto, Portugal: Fundação Manuel Leão, 2011.

CORREIA, José A. Crise da escola e os dispositivos de compensação identitária dos professores. Trabalho \& Educação, FAE/ UFMG, v.17, nº 2, p. 31-52, maio/ago. 2008. 
CORREIA, José A. La "evaluocracia": el papel de la evaluación en la legitimación y reconstrucción institucional de la educación. Avances en Supervisión Educativa, Madrid: ADIDE n. 13, p.1-9, 2010.

CORREIA, José A.; FIDALGO Fernando; FIDALGO, Nara. A avaliação como trabalho e o trabalho da avaliação. Educação, Sociedade \& Culturas, Porto, Portugal, n. 33, p. 37-50, 2011.

DALE, Roger. Globalização e Educação: Demonstrando a existência de uma "Cultura Educacional Mundial Comum" ou localizando uma "Agenda Globalmente Estruturada para a Educação"? Educação \& Sociedade, Campinas, v. 25, n. 87, p. 423-460, maio/ ago. 2004.

DALE, Roger. A Sociologia da Educação e o estado após a globalização. Educação \& Sociedade, Campinas, v. 31, n.113, p. 1099-1120, out./dez. 2010.

DEROUET, Jean-Louis. École et Justice. Paris: Métailié, 1992

DESROSIÈRES, Alain. Discuter l'indiscutible. Tradução Vera Telles. Raisons Pratiques, n. 3, 1993.

DIAS SOBRINHO, José. Avaliação como instrumento da formação cidadã e do desenvolvimento da sociedade democrática: por uma ético-epistemologia da avaliação. In RISTOFF, D.; ALMEIDA JÚNIOR, V. (orgs.). Avaliação participativa: perspectivas e desafios. Brasília: INEP. 2005.

FREIRE, Paulo. Pedagogia da Esperança. 15. ed. Rio de Janeiro: Paz e Terra, 2008.

FREITAS, Luiz C. Qualidade Negociada: avaliação e contra-regulação na escola pública. Educação \& Sociedade, Campinas, v. 26, n.92, p. 911-933, out. 2005.

FREITAS, Luiz C. Os reformadores empresariais da educação: da desmoralização do magistério à destruição do sistema público de educação. Educação \& Sociedade, Campinas, v. 33, n.119, p. 379-404, abr./jun. 2012a.

FREITAS, Luiz C et al. Avaliação e políticas públicas educacionais: ensaios contra-regulatórios em debate. Campinas: Leitura Crítica, 2012b.

FRIGOTTO, Gaudêncio; CIAVATTA, Maria. Educar o trabalhador cidadão produtivo ou o ser humano emancipado? Trabalho, Educação \& Saúde. Rio de Janeiro, v. 1, n. 1, p. 45-60, mar. 2003.

HAMELINE, Daniel. Courants et Contre-courants dans la Pédagogie Contemporaine. Sion: ODIS (Office de Documentation et D’information Scolaires), 1986.

KRUPPA, Sonia M. P. Currículo e avaliação em disputa: "projecto neoliberal" versus "qualidade negociada". In TERRASÊCA, Manuela. (Org.). Autoavaliação das Escolas: Motivos e Sentidos. Colecção Ciências da Educação, nº 8, Porto, Portugal: CllE, no prelo 2014.

LEITE, Denise. Reformas universitárias: Avaliação Institucional Participativa. Porto Alegre: Sulina, 2005.

LIMA, Licínio. Cidadania e educação: Adaptação ao mercado competitivo ou participação na democratização da democracia? Educação, Sociedade \& Culturas. Porto, Portugal, n. 23, p. 71-90, 2005.

MACHADO, Eusébio A. A. A autoavaliação de escola: que lógica(s) de regulação? EL0. Guimarães, Portugal, n. 17, p. 23-31, 2010. MACBEATH, John et al. A História de Serena: Viajando rumo a uma Escola melhor. Porto, Portugal: ASA, 2008.

MORAES, Carmen S. V. Educação de jovens e adultos Trabalhadores de Qualidade: regime de Colaboração e Sistema Nacional de Educação. Educação \& Sociedade. Campinas, v.34, n.124, p. 979-1001, jul./set. 2013.

PORTUGAL. Um estado melhor. Proposta do governo, aprovada no Conselho de Ministros de 30/10/2013, p. 69-78.

RAVITCH, Diane. Vida e morte do grande sistema escolar americano: como os testes padronizados e o modelo de mercado ameaçam a educação. Tradução Marcelo Duarte. Porto Alegre: Sulina, 2011.

ROCHEX, Jean-Yves. PISA et les enquêtes internationales. Enjeux scientifiques, enjeux politiques. Revue Française de Pédagogie, n. 164, p. 81-85, juillet-septembre 2008. 
ROCHEX, Jean-Yves. Viser le noyau dur de la construction des inégalités scolaires. Entrevista a François Jarraud. Café Pédagogique, 06/12/2013. Disponível em: <http://www.cafepedagogique.net/lexpresso/ Pages/2013/12/06122013Article635219127274452419.aspx> Acesso em abr. 2015.

SALOKANGAS, Maija. Autonomy and innovation in English academy schools: a case study. PhD Thesis. Universidade de Manchester, Manchester, Reino Unido, 2013.

SAUL, Ana Maria. Avaliação emancipatória e a prática de avaliação e reformulação de currículo. São Paulo: Cortez/Autores Associados, 1988.

SÉLYS, Gérard de. L'école, grand marché du XXle siècle. Le Monde diplomatique, juin, 1998. Disponível em: <http://www.mondediplomatique.fr/1998/06/De_SELYS/3786>. Acesso em dez. 2014.

SORDI, Mara R. L. Bases ético-epistemológicas de processos de responsabilização participativa e os sentidos que produzem na qualificação da escola pública. In: CONGRESSO INTERNACIONAL DE EDUCAÇÃO, 8. e CONGRESSO INTERNACIONAL DE AVALIAÇÃO, 3., Gramado, 2013. Anais... São Leopoldo: Casa Leiria, 2013. v. 1.

SOUZA, Eliana; SORDI, Mara R. L (Orgs.). A avaliação institucional como instância mediadora da qualidade da escola pública: A rede municipal de educação de Campinas como espaço de aprendizagem. Campinas: Millennium Editora Ltda., 2012.

TERRASÊCA, Manuela; BERGER, Guy. (Eds) Políticas e práticas de avaliação. Algumas reflexões. Educação, Sociedade \& Culturas, Porto, Portugal, n. 33, 2011

TERRASÊCA, Manuela. Avaliação externa - porquê e para quê? Reflectindo sobre a avaliação externa de escolas em Portugal. In FREITAS, Luiz C et al. (Orgs.). Avaliação e políticas públicas educacionais: ensaios contrarregulatórios em debate. Campinas: Leitura Crítica, p. 133-156, 2012.

Recebido em: 14.01.2015

Aprovado em: 11.03.2015

Geisa do S. C. Vaz Mendes é doutora em Educação, pesquisadora do Laboratório de Observação e Estudos Descritivos (LOED) da Faculdade de Educação da Universidade Estadual de Campinas (Unicamp), integrante do projeto "A Qualidade da Escola Pública: um estudo longitudinal para sustentação da responsabilização partilhada em um rede de ensino (OBEDUC/ CAPES - 2013/2017)" e professora da Faculdade de Educação da Pontifícia Universidade Católica de Campinas (PUC-Campinas).

João Caramelo é professor auxiliar da Faculdade de Psicologia e de Ciências da Educação da Universidade do Porto (FPCEUP), pesquisador no Grupo de Investigação Políticas, Comunidades e Participação (PCP) do Centro de Investigação e Intervenção Educativas (CIIE) da FPCEUP.

Lisete Regina Gomes Arelaro é pedagoga e doutora em Educação. Atualmente é professora titular do Departamento de Administração Escolar e Economia da Educação da Faculdade de Educação da Universidade de São Paulo (USP), noS cursos de Pedagogia, Graduação e de Pós-Graduação em Educação (mestrado e doutorado). É pesquisadora na área de Políticas Públicas em Educação. Integrou a equipe de Paulo Freire na Secretaria Municipal de Educação de São Paulo (Gestão Luiza Erundina -1989/1992).

Manuela Terrasêca é professora associada da Faculdade de Psicologia e de Ciências da Educação (FPCEUP) da Universidade do Porto (UP). É pesquisadora no Grupo de Investigação Políticas, Comunidades e Participação (PCP), do Centro de Investigação e Intervenção Educativas (CIIE) da FPCEUP.

Mara Regina Lemes De Sordi é pós-doutora em Educação, professora do Departamento de Ensino e Práticas Culturais da Faculdade de Educação da Universidade Estadual de Campinas (Unicamp), membro do grupo de pesquisa do Laboratório de Observação e Estudos Descritivos (LOED) da Faculdade de Educação da Universidade Estadual de Campinas (Unicamp).

Sonia Maria Portella Kruppa é professora da Faculdade de Educação da Universidade de São Paulo. Socióloga e pedagoga, foi professora em todos os níveis da educação básica e do ensino superior públicos. Fez parte da equipe de Paulo Freire na Secretaria Municipal de Educação de São Paulo (Gestão Luiza Erundina - 1989/1992). São seus temas de pesquisa: a ação dos Organismos Internacionais na educação, políticas públicas em educação e relações entre trabalho e educação. 